Article

\title{
Clarification of Active Sites at Interfaces between Silica Support and Nickel Active Components for Carbon Monoxide Methanation
}

\author{
Mengjuan Zhang ${ }^{1,+}{ }^{,}$Panpan Li ${ }^{1,+}{ }^{\dagger}$, Zhiqun Tian ${ }^{2}$, Mingyuan Zhu ${ }^{1}$, Fu Wang ${ }^{3}$, Jiangbing Li ${ }^{1}$, \\ Bin Dai ${ }^{1}$, Feng Yu ${ }^{1, *(1)}$, Hengshan Qiu ${ }^{3, *(1)}$ and Hongwei Gao ${ }^{4, *}$ \\ 1 Key Laboratory for Green Processing of Chemical Engineering of Xinjiang Bingtuan, School of Chemistry \\ and Chemical Engineering, Shihezi University, Shihezi 832003, China; mengjuanzhang2017@126.com (M.Z.); \\ ppl_19910109@163.com (P.L.); zhuminyuan@shzu.edu.cn (M.Z.); ljbing@126.com (J.L.); \\ db_tea@shzu.edu.cn (B.D.) \\ 2 Collaborative Innovation Center of Renewable Energy Materials, Guangxi University, Nanning 530004, \\ China; tianzhiqun@gxu.edu.cn \\ 3 Xinjiang Technical Institute of Physics and Chemistry, Chinese Academy of Sciences, Urumqi 830011, China; \\ wangfu@ms.xjb.ac.cn \\ 4 School of Life Science, Ludong University, Yantai 264025, China \\ * Correspondence: yufeng05@mail.ipc.ac.cn (F.Y.); qiu@ms.xjb.ac.cn (H.Q.); gaohongw369@163.com (H.G.); \\ Tel.: +86-993-205-7272 (F.Y.); +86-991-369-0837 (H.Q.); +86-535-668-5003 (H.G.); \\ Fax.: +86-993-205-7270 (F.Y.); +86-991-369-0837 (H.Q.); +86-535-668-5003 (H.G.) \\ + These authors contributed equally to this work.
}

Received: 13 June 2018; Accepted: 16 July 2018; Published: 20 July 2018

check for updates

\begin{abstract}
Identification of active site is critical for developing advanced heterogeneous catalysis. Here, a nickel/silica $\left(\mathrm{Ni} / \mathrm{SiO}_{2}\right)$ catalyst was prepared through an ammonia-evaporation method for $\mathrm{CO}$ methanation. The as-obtained $\mathrm{Ni} / \mathrm{SiO}_{2}$ catalyst shows a $\mathrm{CO}$ conversion of $96.74 \%$ and a methane selectivity of $93.58 \%$ at $623 \mathrm{~K}$ with a weight hourly space velocity of $25,000 \mathrm{~mL} \cdot \mathrm{g}^{-1} \cdot \mathrm{h}^{-1}$. After $150 \mathrm{~h}$ of continuous testing, the CO conversion still retains $96 \%$, which indicates a high catalyst stability and long life. An in situ vacuum transmission infrared spectrum demonstrates that the main active sites locate at the interface between the metal $\mathrm{Ni}$ and the $\mathrm{SiO}_{2}$ at a wave number at $2060 \mathrm{~cm}^{-1}$ for the first time. The interesting discovery of the active site may offer a new insight for design and synthesis of methanation catalysts.
\end{abstract}

Keywords: active sites; carbon monoxide methanation; ammonia-evaporation method; in situ vacuum transmission infrared spectroscopy; density-functional theory

\section{Introduction}

With the increasing global demand for clean energy sources, natural gas, the main ingredient of methane $\left(\mathrm{CH}_{4}\right)$, is promising as a clean energy source, which replaces conventional fossil fuels that have resulted in a range of environmental issues [1,2]. Carbon monoxide (CO) methanation is an ideal way to produce $\mathrm{CH}_{4}$ from coal, and has proven to be one of the most effective ways for the clean utilization of coal $[3,4]$. Previous research has focused on improving the required catalytic performance of nickel-based catalysts in $\mathrm{CO}$ methanation [5-7]. Especially, nickel/silica $\left(\mathrm{Ni} / \mathrm{SiO}_{2}\right)$ catalyst attracted significant attention due to its high efficient activity for $\mathrm{CO}$ methanation [8,9].

Enlarged active sites of $\mathrm{Ni} / \mathrm{SiO}_{2}$ are significant routes to enhance activity of $\mathrm{CO}$ catalytically converted to synthetic natural gas (SNG) for clean energy in C1 Chemistry [4]. Generally, a smaller $\mathrm{Ni}$ particle size gives a better performance and provides the important route of strengthen the 
activity of CO methanation. Yan et al. [10] and Zhao et al. [11] found that a smaller Ni particle size, a higher Ni particles dispersion and an enhanced interaction between $\mathrm{Ni}$ and the $\mathrm{SiO}_{2}$ support via dielectric-barrier discharge (DBD) plasma decomposition method exhibited significantly improved activity with enhanced stability. Li et al. [12] reported a superior position for implantation of $\mathrm{Ni}$ species on two-dimensional porous $\mathrm{SiO}_{2}$ nanomesh rather than three-dimensional MCM-41, resulting in high Ni dispersion and activity.

Despite numerous studies on the use of smaller Ni particles to improve the catalytic performance, little comprehensive understanding exists of the microscopic mechanism. Yao et al. [13] studied $\mathrm{Cu}-\mathrm{Ni} / \mathrm{SiO}_{2}$ catalysts via in situ $\mathrm{CO}$ polarization modulation infrared reflection absorption spectroscopy (PM-IRRAS) and found that CO-induced surface segregation of Ni easily resulted in severe errors in Ni active site measurements via the selective CO chemisorption. Loc et al. [14] measured kinetic isotope effects on Ni-based catalysts via the replacement of hydrogen by deuterium in $\mathrm{CO}$ methanation and found that interaction of oxygen-containing compounds with hydrogen was a slow step of the process. Martra et al. [15] reported that the high Ni dispersion provided good $\mathrm{CO}$ adsorption on metal-support interaction via in situ diffuse reflectance Fourier transform infrared spectroscopy (DRIFTS). Primet et al. [16] studied $\mathrm{CO}$ adsorption on $\mathrm{Ni} / \mathrm{SiO}_{2}$ catalysts via infrared spectroscopy and saturation magnetization and found that the presence of two bands in the region corresponding to linear species ( 2070 and $2040 \mathrm{~cm}^{-1}$ ) with intensities ratios varying with the degree of $\mathrm{NiO}$ reduction. These concerns, along with essential demands to incorporate activity for $\mathrm{CO}$ methanation, led scientists towards the study of active sites.

Herein, we have prepared an $\mathrm{Ni} / \mathrm{SiO}_{2}$ catalyst by the ammonia-evaporation (AE) method, and have explored the active sites for $\mathrm{CO}$ methanation by in situ vacuum transmission infrared (VTIR) spectroscopy and density-functional theory (DFT) calculations. The in situ VTIR results indicated that the main active site was the interface between the metal $\mathrm{Ni}$ and silica $\left(\mathrm{SiO}_{2}\right)$ support. DFT was used to confirm the $\mathrm{CO}$ adsorption behavior in various types of adsorption sites. We believe that clarifications of active sites at the interface between silica support and nickel active component afford an effective way to design and prepare a high-efficiency CO methanation catalyst.

\section{Results and Discussion}

\subsection{Schematic Illustration}

In order to explore the reaction mechanism of the $\mathrm{CO}$ methanation by Ni-based catalysts, our main design was to combine the actual value with the theoretical calculated value to speculate the bonded sites of CO species. First, from the results of in situ Fourier Transform infrared spectroscopy (FTIR) spectra, we found there were four types of adsorption sites: the $\mathrm{NiO}$ or $\mathrm{SiO}_{2}$ surface, the top $\mathrm{Ni}$ atom surface, the interface between the $\mathrm{SiO}_{2}$ and $\mathrm{Ni}$ atom, and the bridge of the surface Ni atoms. Combined with the results of in situ FTIR differential spectra of catalyst $\mathrm{Ni} / \mathrm{SiO}_{2}$ at $500 \mathrm{~K}$ in the presence of $\mathrm{CO}$ and $\mathrm{H}_{2}$ at different reaction times, an obvious negative peak at $2060 \mathrm{~cm}^{-1}$ suggesting an interface between $\mathrm{SiO}_{2}$ and $\mathrm{Ni}$, which means that the interface between the $\mathrm{SiO}_{2}$ and $\mathrm{Ni}$ atoms played a key role in the $\mathrm{CO}$ methanation reaction. The interface adsorption has two main types: $\mathrm{Ni}-\mathrm{SiO}_{2}$ and $\mathrm{Ni}-\mathrm{O}$. From the results of DFT, the theoretical value of $\mathrm{Ni}-\mathrm{SiO}_{2}$ and $\mathrm{Ni}-\mathrm{O}$ interface adsorption presented at $1859 \mathrm{~cm}^{-1}$ and $2019 \mathrm{~cm}^{-1}$, respectively. It indicated that the Ni-O interface adsorption was the mean point adsorption site and the red-shift about the vibration peak was due to the synergistic effect of $\mathrm{Ni}-\mathrm{SiO}_{2}$ interface adsorption.

\subsection{Catalytic Performance}

A previous study indicated that smaller $\mathrm{Ni}$ particles provide a better catalytic performance, with a higher $\mathrm{CO}$ conversion and $\mathrm{CH}_{4}$ selectivity [17]. The catalytic performance of $\mathrm{Ni} / \mathrm{SiO}_{2}$ was tested at the range of 523-823 K, $1.5 \mathrm{MPa}$, with a weight hourly space velocity (WHSV) of $25,000 \mathrm{~mL} \cdot \mathrm{g}^{-1} \cdot \mathrm{h}^{-1}$. Before the test, only a small part of the $\mathrm{NiO}$ on the catalyst was reduced to $\mathrm{Ni}$, and low $\mathrm{Ni}$ loading and 
high $\mathrm{Ni}$ dispersion provided efficient active sites [18]. The $\mathrm{Ni} / \mathrm{SiO}_{2}$ catalyst displayed an excellent catalytic performance over the entire reaction temperature.

As shown in Figure 1a, the catalyst displayed a 91.7\% CO conversion at $523 \mathrm{~K}$, and achieved a maximum $\mathrm{CO}$ conversion at $623 \mathrm{~K}$ with a $\mathrm{CO}$ conversion of $96.7 \%$. The $\mathrm{CO}$ conversion decreased with temperature, and showed an $89.0 \% \mathrm{CO}$ conversion at $823 \mathrm{~K}$. The $\mathrm{CH}_{4}$ selectivity of the $\mathrm{Ni} / \mathrm{SiO}_{2}$ catalyst showed the same tendency with $\mathrm{CO}$ conversion, and achieved a maximum $\mathrm{CH}_{4}$ selectivity of $95.6 \%$ at $623 \mathrm{~K}$. The turnover frequency (TOF) values were calculated by Ni dispersion which were obtained by hydrogen adsorption method. It showed that TOF increased with an increasing temperature, and achieved a maximum value of $17.6 \mathrm{~s}^{-1}$ at $623 \mathrm{~K}$, then decreased with rising temperatures, and showed an $89.0 \%$ CO conversion and $16.2 \mathrm{~s}^{-1} \mathrm{TOF}$ at $823 \mathrm{~K}$. The as-obtained catalyst maintained efficient catalytic activity for $150 \mathrm{~h}$ at $623 \mathrm{~K}, 1.5 \mathrm{MPa}$ with a WHSV of $25,000 \mathrm{~mL} \cdot \mathrm{g}^{-1} \cdot \mathrm{h}^{-1}$. Figure $1 \mathrm{~b}$ shows only a $3 \%$ decreased $\mathrm{CO}$ conversion, which indicated that the $\mathrm{Ni} / \mathrm{SiO}_{2}$ catalyst presented an excellent thermodynamic stability. Besides, the $\mathrm{Ni} / \mathrm{SiO}_{2}$ catalyst by $\mathrm{AE}$ method showed strong interactions between $\mathrm{Ni}$ and the silica support, which promoted the formation of a stable structure and prevented Ni aggregation.
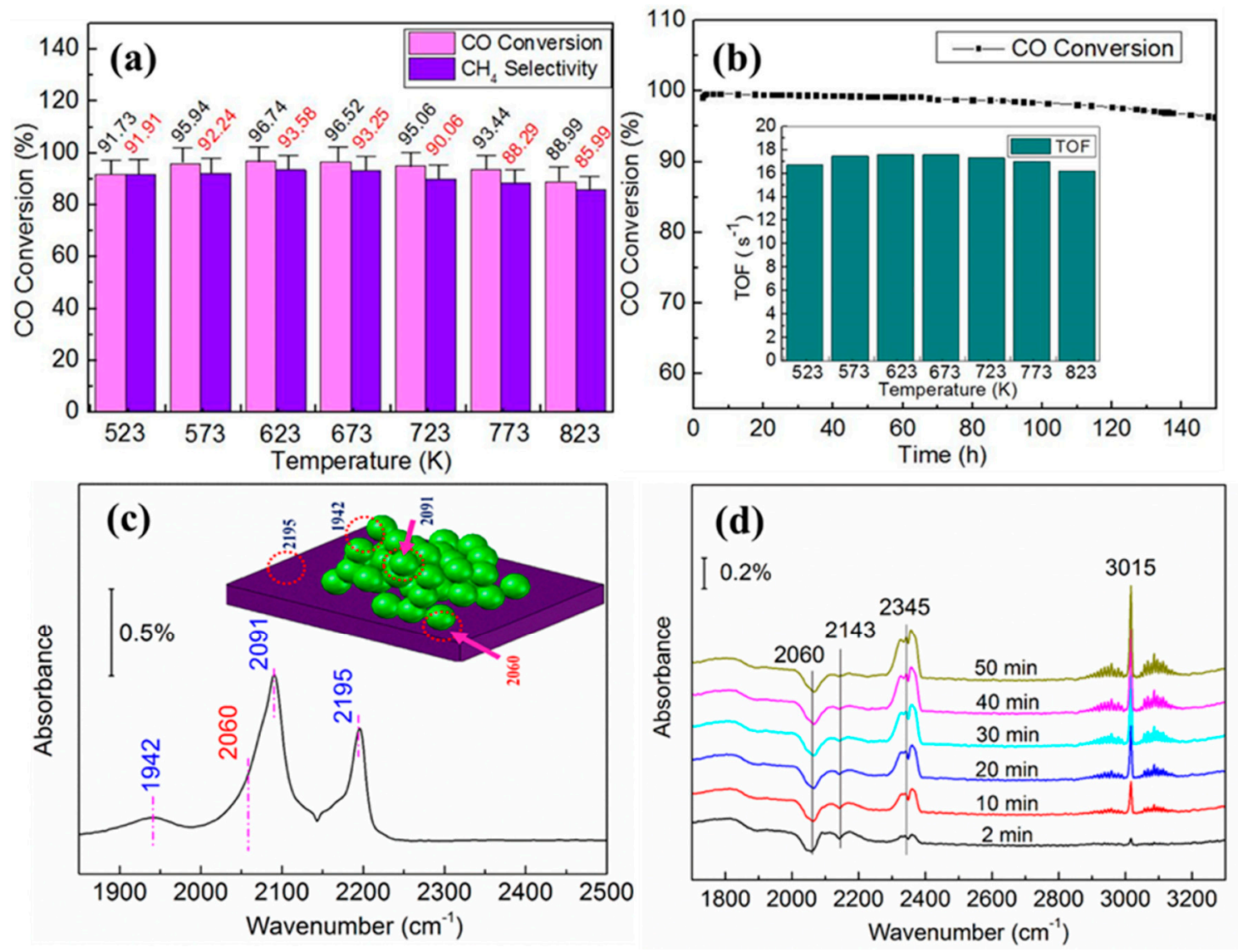

Figure 1. (a) $\mathrm{CO}$ conversion and $\mathrm{CH}_{4}$ selectivity of $\mathrm{Ni} / \mathrm{SiO}_{2} ;$ (b) turnover frequency (TOF) values and stability at $623 \mathrm{~K}$ of $\mathrm{Ni} / \mathrm{SiO}_{2}$. (c) In situ Fourier Transform infrared spectroscopy (FTIR) spectra of $\mathrm{Ni} / \mathrm{SiO}_{2}$ catalyst at $1 \mathrm{mbar} \mathrm{CO}$ and room temperature. The reference spectrum was obtained on a clean sample under high vacuum at room temperature. (d) In situ FTIR differential spectra of catalyst $\mathrm{Ni} / \mathrm{SiO}_{2}$ at $500 \mathrm{~K}$ in the presence of $\mathrm{CO}$ and $\mathrm{H}_{2}$ at different reaction times. The reference spectrum was the sample spectrum at $1 \mathrm{mbar} \mathrm{CO}$ and $500 \mathrm{~K}$. The differential spectrum was recorded immediately after the introduction of $3 \mathrm{mbar}_{2}$ at $500 \mathrm{~K}$. 


\subsection{Catalyst Characterization}

Prior work reported that smaller $\mathrm{Ni}^{0}$ particles yield a better catalytic performance, because smaller $\mathrm{Ni}^{0}$ particles provide more active sites [12]. Some efforts had been shown to study the active sites on Ni-based catalysts. Agnelli et al. [19] found that the active sites of $\mathrm{Ni} / \mathrm{SiO}_{2}$ comprised one to two adjacent $\mathrm{Ni}$ atoms, which were free from adsorbed CO. Liu et al. [20] proposed that defect sites on the metallic $\mathrm{Ni}^{0}$ particles dominated the reaction activity. The reaction mechanism on the $\mathrm{Ni}(111)$; was studied by experiments and DFT [21,22]. However, the definite active sites in Ni-based catalysts are still unclear.

In order to explore the active sites on $\mathrm{Ni} / \mathrm{SiO}_{2}$ for methanation reactions, in situ vacuum FTIR experiments were used to investigate the $\mathrm{CO}$ adsorption behavior on the catalysts. Here, we regarded the in situ FT-IR signals of the samples that were exposed to $1 \mathrm{mbar} C \mathrm{O}$ at $500 \mathrm{~K}$ as the reference spectrum. The needed differential spectra were obtained by subtracting the reference spectral curve. Four kinds of adsorption sites were selected: the $\mathrm{NiO}$ or $\mathrm{SiO}_{2}$ surface, the top $\mathrm{Ni}$ atom surface, the interface between the $\mathrm{SiO}_{2}$ and $\mathrm{Ni}$ atom, and the bridge of the surface $\mathrm{Ni}$ atoms $[23,24]$. Figure $1 \mathrm{c}$ shows the in situ IR spectrum of $\mathrm{Ni} / \mathrm{SiO}_{2}$, which was exposed to 1 mbar $\mathrm{CO}$ at $\mathrm{RT}$. Three apparent IR bands exist in the spectrum: (a) $\mathrm{CO}$ adsorption on the $\mathrm{NiO}$ or $\mathrm{SiO}_{2}$ surface at $2195 \mathrm{~cm}^{-1}$, with a slight blue-shift compared with the gas phase $\mathrm{CO}$; (b) $\mathrm{CO}$ adsorption on the top sites of the surface $\mathrm{Ni}$ at $2091 \mathrm{~cm}^{-1}$, with a slight red-shift compared with the gas phase CO; (c) CO adsorption on the bridge sites of surface $\mathrm{Ni}$ at $1942 \mathrm{~cm}^{-1}$, with a large red-shift compared with the gas phase CO [2]. Two more bands in the spectrum, including the vibration of gaseous $\mathrm{CO}$ as indicated by the steep trough centered at $2143 \mathrm{~cm}^{-1}$, and a band at $2060 \mathrm{~cm}^{-1}$, had been overshadowed by other intense bands, such as the asymmetric shape of the band at $2091 \mathrm{~cm}^{-1}$. The exact value of the latter bands could be determined in the following text.

A VTIR spectrum of the $\mathrm{CO}$ and $\mathrm{H}_{2}$ reactions was obtained to explore the catalytic capability of four types of active sites. Four peaks in Figure $1 \mathrm{~d}$ include a vibration peak with a wave number at $3015 \mathrm{~cm}^{-1}$ from the $\mathrm{CH}_{4}$ [24], a wave number at $2345 \mathrm{~cm}^{-1}$ from the $\mathrm{CO}_{2}$ vibration peak [25], then a $\mathrm{CO}$ vibration peak with a wave number at $2143 \mathrm{~cm}^{-1}$, and a peak with a wave number at $2060 \mathrm{~cm}^{-1}$ that was ascribed to CO adsorption. The reference spectrum was the sample spectrum under 1 mbar CO at $500 \mathrm{~K}$. Positive peaks in the spectra implied that new species were formed during the process, and negative peaks indicated that the corresponding species were consumed. The in situ transmission infrared spectrum of the $\mathrm{CO}$ and $\mathrm{H}_{2}$ reactions demonstrated that active sites at the interface between $\mathrm{SiO}_{2}$ and $\mathrm{Ni}$ and at $2060 \mathrm{~cm}^{-1}$ were most efficient. With the reaction time increasing, $\mathrm{CO}$ was consumed and $\mathrm{CH}_{4}$ was generated. However, no negative peaks were observed at $2195 \mathrm{~cm}^{-1}$, $2091 \mathrm{~cm}^{-1}$, and $1942 \mathrm{~cm}^{-1}$. The emergence of $\mathrm{CO}_{2}$ bands indicated that the methanation reaction might exist as a side reaction pathway under the present reaction conditions.

Figure $2 \mathrm{a}$ and $\mathrm{b}$ show the transmission-electron microscopy (TEM) and high-resolution TEM (HRTEM) images of the $\mathrm{Ni} / \mathrm{SiO}_{2}$ catalyst. On the surface of catalyst, there were a lot of visible black spots, which attributed to Ni particles. Lattice fringes in Figure $2 \mathrm{~b}$ with a typical d-spacing of $0.282 \mathrm{~nm}$ and $0.244 \mathrm{~nm}$ were ascribed to the (102) and (112) crystallographic plane of $\mathrm{SiO}_{2}[26,27]$. Furthermore, high-angle annular dark field scanning transmission electron microscopy (HAADF-STEM) was used to observe the Ni particles on the surface clearly. Small light spots, which were attributed to small $\mathrm{Ni}$ particles, were dispersed uniformly on the catalyst surface (Figure 2c). The detailed particle-size distributions of the $\mathrm{Ni} / \mathrm{SiO}_{2}$ catalyst were determined from the HAADF-STEM image, and the average $\mathrm{Ni}$ particle size was $2-3 \mathrm{~nm}$. Figure $2 \mathrm{~d}$ shows the scanning-electron microscopy (SEM) image of the $\mathrm{Ni} / \mathrm{SiO}_{2}$ catalyst, and the insert shows the Ni mapping. Ni was dispersed uniformly, which agreed well with the HAADF-STEM results. Wide-angle X-ray powder diffraction (XRD) patterns of the $\mathrm{Ni} / \mathrm{SiO}_{2}$ are shown in Figure 2e. The diffraction peak at $21.99^{\circ}$ belonged to $\mathrm{SiO}_{2}$ (JCPDS NO. 77-1316), and the nickel phyllosilicate characteristic peaks (JCPDS NO. 49-1859) were observed at a $2 \theta$ of $19.52^{\circ}$, $34.1^{\circ}, 36.9^{\circ}$ and $60.50^{\circ}[11,28,29]$. The peak intensity was weak and exhibited a wide half-peak breadth in the XRD pattern because of the small and finely dispersed of Ni particles [27]. 
The $\mathrm{NiO} / \mathrm{SiO}_{2}$ catalyst reducibility was characterized by $\mathrm{H}_{2}-\mathrm{TPR}$, as shown in Figure $2 \mathrm{f}$. The TPR profile of $\mathrm{NiO} / \mathrm{SiO}_{2}$ catalyst showed two reduction peaks. The reduction peak centered at $550.8 \mathrm{~K}$ resulted from surface $\mathrm{NiO}$ reduction [30-32]. Another reduction peak at around $951 \mathrm{~K}$ was ascribed to $\mathrm{Ni}^{2+}$ ions in bulk phyllosilicates, i.e., $\mathrm{NiO}$ species interacted strongly with the support [33-35]. The $\mathrm{H}_{2}$-TPR profile showed that only some $\mathrm{Ni}^{2+}$ was reduced to metal $\mathrm{Ni}$ during the pretreatment because of the strong interaction, and thus no Ni diffraction peak was visible in the XRD pattern. Moreover, the results of $\mathrm{Ni}$ dispersion by hydrogen adsorption method was detected of $13.7 \%$, which determined a high TOF values and high catalytic performance.
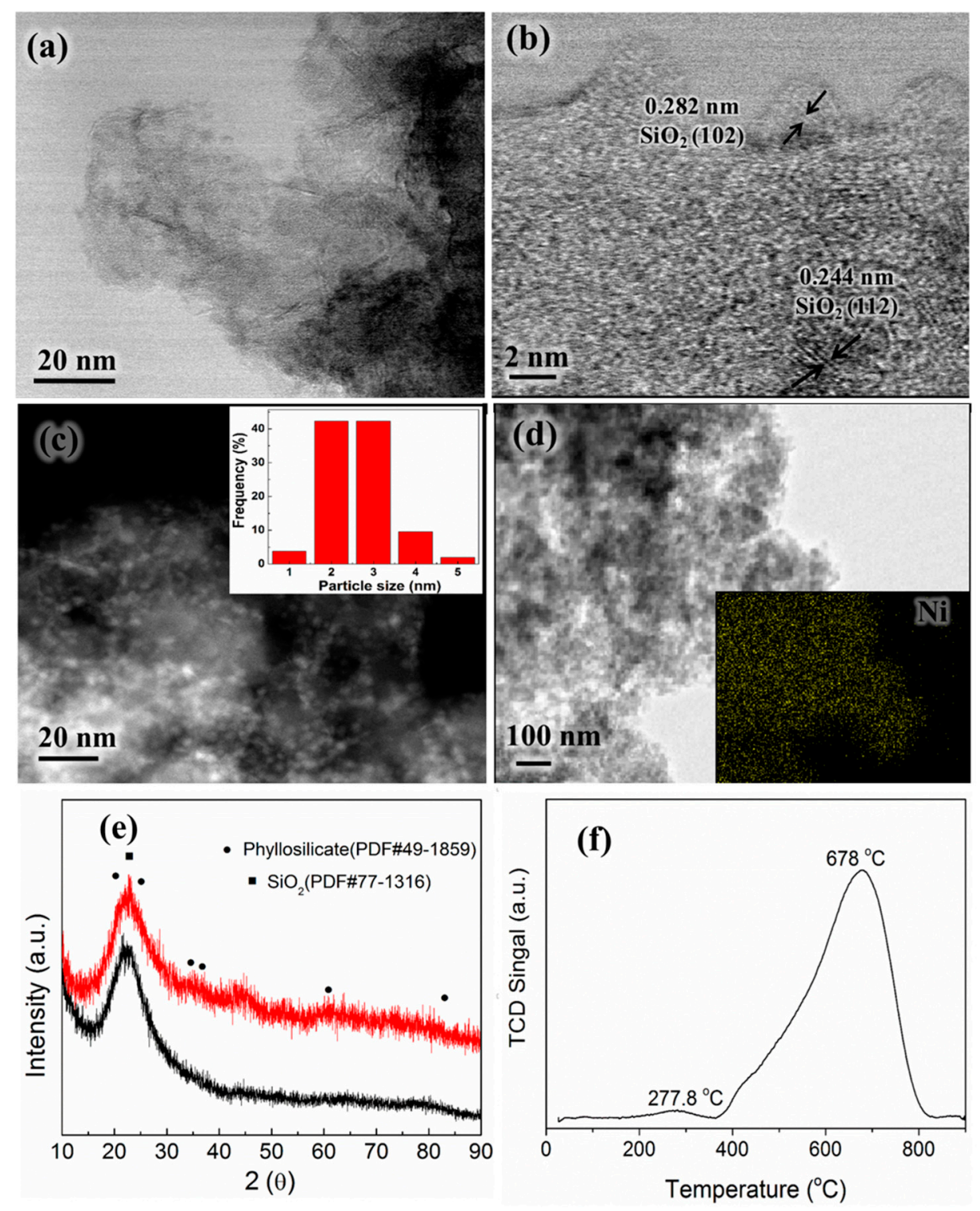

Figure 2. HRTEM (high-resolution transmission-electron microscopy) images of $(\mathbf{a}, \mathbf{b}) \mathrm{Ni} / \mathrm{SiO}_{2}$, (c) HAADF-STEM (high-angle annular dark field scanning transmission electron microscopy) images and $\mathrm{Ni}$ particle-size distribution (inset) for $\mathrm{Ni} / \mathrm{SiO}_{2}$, (d) SEM (scanning-electron microscopy) image of $\mathrm{Ni} / \mathrm{SiO}_{2}$ and $\mathrm{Ni}$ mapping (inset), (e) XRD (X-ray powder diffraction) patterns of $\mathrm{SiO}_{2}$ and $\mathrm{Ni} / \mathrm{SiO}_{2}$, (f) $\mathrm{H}_{2}$ temperature-programmed reduction $\left(\mathrm{H}_{2}-\mathrm{TPR}\right)$ of catalyst $\mathrm{NiO} / \mathrm{SiO}_{2}$. 


\subsection{Various Types of Active Sites}

DFT was used to study the $\mathrm{CO}$ adsorption behavior in four types of adsorption sites, as shown in Figure 3. Figure 3a shows the $\mathrm{CO}$ adsorption models of four different active sites. Figure 3b-e show the calculated IR spectra of four types of $\mathrm{CO}$ adsorption models. $\mathrm{C}-\mathrm{O}$ intramolecular stretching was sensitive on the adsorption sites [36], as described more extensively in original papers [37-40]. The calculated symmetric vibrational modes for $\mathrm{CO}$ adsorption at the top $\mathrm{Ni}$ atom surface was $1992 \mathrm{~cm}^{-1}\left(2131 \mathrm{~cm}^{-1}\right.$ after correction), and the experimental value was $2091 \mathrm{~cm}^{-1}$. The calculated symmetric vibrational modes for CO adsorption at the bridge of surface Ni was $1841 \mathrm{~cm}^{-1}(1980 \mathrm{after}$ correction), with the experimental value of $1942 \mathrm{~cm}^{-1}$.
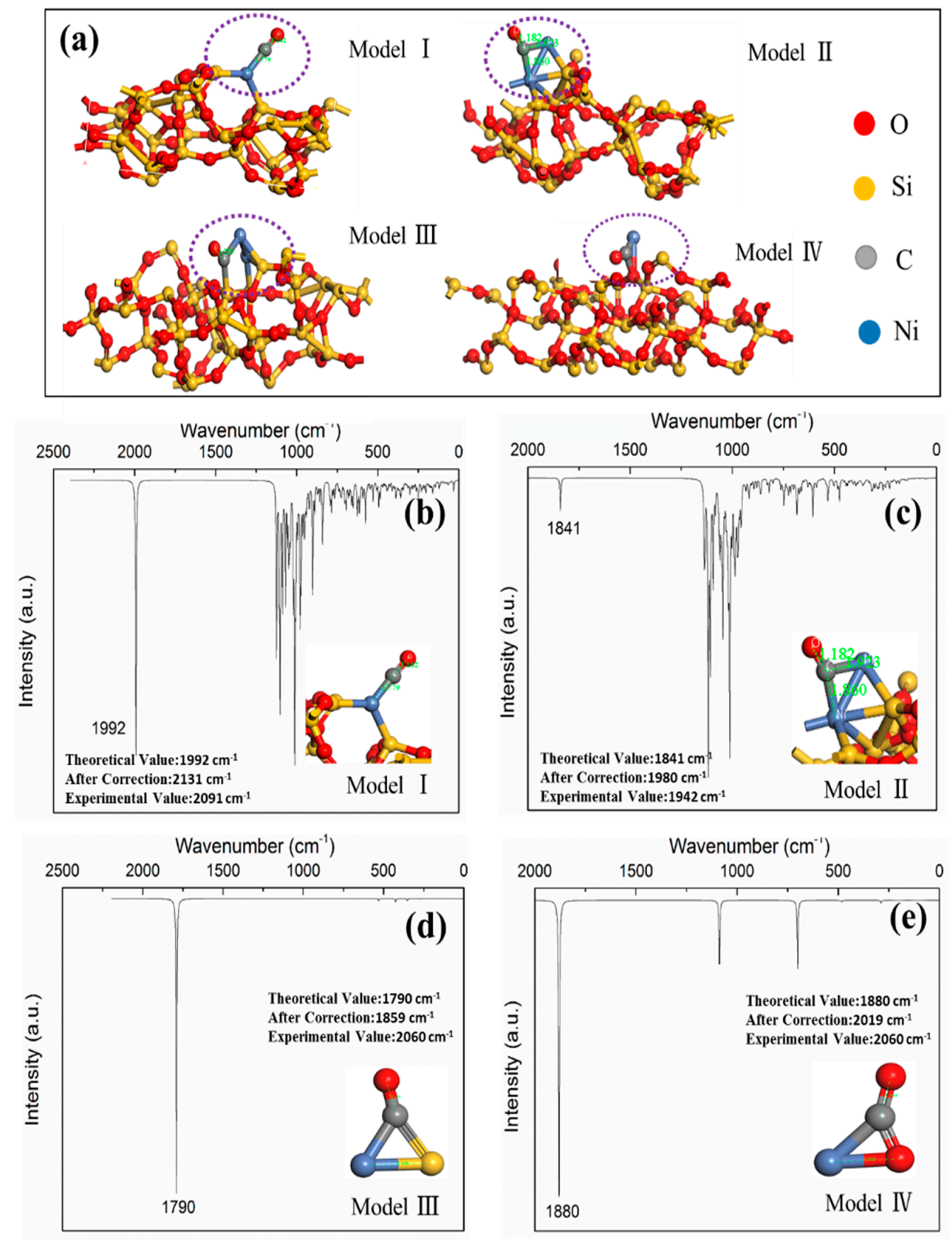

Figure 3. (a) $\mathrm{CO}$ adsorption model at different sites. DFT results of (b) $\mathrm{SiO}_{2}$ (111)-modified-CO-Nitop-spectrum, (c) $\mathrm{SiO}_{2}$ (111)-modified-Ni-bridge-spectrum, (d) $\mathrm{Si}-\mathrm{Ni}$-spectrum and (e) O-Ni-spectrum. 
There were two situations for $\mathrm{CO}$ adsorption at the interface between the $\mathrm{Ni}$ and the support $\mathrm{SiO}_{2}$. (1) $\mathrm{CO}$ adsorption between $\mathrm{Ni}-\mathrm{Si}$ where the theoretical value of the $\mathrm{CO}$ symmetric vibrational mode was $1859 \mathrm{~cm}^{-1}$ after correction, and differs by $201 \mathrm{~cm}^{-1}$ compared with the experimental value of $2060 \mathrm{~cm}^{-1}$. (2) $\mathrm{CO}$ adsorption between $\mathrm{Ni}-\mathrm{O}$ where the theoretical value of the $\mathrm{CO}$ adsorption was $2019 \mathrm{~cm}^{-1}$ after correction, and the difference between the theoretical and experimental values was $41 \mathrm{~cm}^{-1}$. Because the theoretical value of $\mathrm{CO}$ adsorption between $\mathrm{Ni}-\mathrm{O}$ agreed well with the experimental value, we assume that $\mathrm{CO}$ was adsorbed between the $\mathrm{Ni}-\mathrm{O}$ atoms of the interface between $\mathrm{SiO}_{2}$ and Ni. And the in situ VTIR spectrum of the $\mathrm{CO}$ and $\mathrm{H}_{2}$ reactions agreed well with previous experimental results, which indicated that with the same Ni content, the smaller $\mathrm{Ni}$ particles provided a more support-active ingredient interface and promoted the catalytic performance. Furthermore, with the same size of Ni particles, an increasing Ni loading also could promote catalytic performance. From the experimental results, the as-obtained catalyst with remarkable small $\mathrm{Ni}$ particles $(2-3 \mathrm{~nm})$ presented more effective active sites, which agreed with the excellent catalytic performance of $\mathrm{Ni} / \mathrm{SiO}_{2}$ catalyst.

\section{Materials and Methods}

\section{1. $\mathrm{Ni} / \mathrm{SiO}_{2}$ Catalyst Preparation}

$\mathrm{A} \mathrm{Ni} / \mathrm{SiO}_{2}$ catalyst was prepared through the $\mathrm{AE}$ method, with the preparation process as follows. A defined amount of $\mathrm{Ni}\left(\mathrm{NO}_{3}\right)_{2} \cdot 6 \mathrm{H}_{2} \mathrm{O}$ as the $\mathrm{Ni}$ source was dissolved in deionized water to obtain metal precursor solution. Excess of $28 \%$ aqueous ammonia solution (analytical-reagent grade, Sinopharm Chemical Reagent Ltd., Shanghai, China) was added to the precursor solution until appeared flocculent material and the quantity was basically constant, and then stirred for $30 \mathrm{~min}$. Afterwards, the requisite quantities of silica sol (Ludox AS-40) was added to the nickel-ammonia-complex solution, where the loading of nickel was $10 \mathrm{wt} \%$. And then, the obtained solution was stirred for another $4 \mathrm{~h}$ at $353 \mathrm{~K}$ in an oil bath, where the suspension was evaporated. The obtained material was washed with deionized water until there was no $\mathrm{pH}$ change $(\mathrm{pH}=7)$ and dried at $353 \mathrm{~K}$ for $24 \mathrm{~h}$ to obtain catalyst precursors. The catalyst precursors were calcined at $823 \mathrm{~K}$ for $4 \mathrm{~h}$ in a muffle furnace to produce $\mathrm{NiO} / \mathrm{SiO}_{2}$ catalyst.

\subsection{Catalyst Characterization}

X-ray diffractometry was used to analyze the crystallographic properties of the materials and XRD patterns were obtained with a BrukerD8 Advance X-ray diffractometer (Bruker Biosciences Corporation, Billerica, MA, USA) with $\mathrm{Cu} \mathrm{K} \alpha$ radiation in the $2 \theta$ range of $0-90^{\circ} . \mathrm{H}_{2}$-TPR experiments were performed to determine the reducibility of the NiO oxides using a Micromeritics TPx System (Micromeritic ASAP 2720, Micromeritics Instrument Ltd., Norcross, GA, USA) from room temperature to $1173 \mathrm{~K}$ at $10 \mathrm{~K} / \mathrm{min}$ with a $10 \mathrm{vol} \% \mathrm{H}_{2} /$ Ar flow of $40 \mathrm{~mL} / \mathrm{min}$ and by retaining the sample at $1173 \mathrm{~K}$ for $20 \mathrm{~min}$. In order to analyze the dispersion of $\mathrm{Ni} / \mathrm{SiO}_{2}$ catalyst, hydrogen adsorption was carried out by Autochem 2920 (Micromeritics Instrument Ltd., Norcross, GA, USA). $0.1 \mathrm{~g}$ catalysts were reduced at $750{ }^{\circ} \mathrm{C}$ for $1 \mathrm{~h}$ in $\mathrm{H}_{2}$ atmosphere and cooled with $\mathrm{N}_{2}$ atmosphere. Then $\mathrm{H}_{2}(30 \mu \mathrm{L}$ per pulse, carrier gas, $\mathrm{N}_{2} 40 \mathrm{~cm}^{3} \mathrm{~min}^{-1}$ ) was adsorbed by the $\mathrm{Ni} / \mathrm{SiO}_{2}$ catalyst. The catalyst morphology was studied by SEM (Hitachi S-4300 microscope, Hitachi Limited, Japan). TEM and HRTEM images were obtained with a Tecnai F30 field-emission transmission-electron microscope (Hillsboro, OR, USA).

In situ VTIR spectra were recorded by a Thermo Nicolet Is50 spectrometer equipped with a MCT detector cooled by liquid nitrogen and a heating chamber. The catalyst was loaded in a Harrick IR cell and pretreated at $673 \mathrm{~K}$ under $\mathrm{N}_{2}$ at a total flow rate of $100 \mathrm{~mL} / \mathrm{min}$ for $60 \mathrm{~min}$ to remove adsorbed impurities. VTIR spectra were recorded by accumulating 32 scans with a resolution of $4 \mathrm{~cm}^{-1}$. The in situ VTIR spectrometer was constructed from a commercial IR spectrometer (Vertex $70 \mathrm{v}$, Bruker Corp., Germany). The original measurement compartment was replaced by a stainless-steel chamber that was separated from the IR spectrometer by two $\mathrm{KBr}$ windows. An IR beam from the light source in the spectrometer was passed through a sample in the IR chamber and detected 
by a deuterated L-alanine-doped triglycine sulfate detector. The base pressure in the spectrometer was better than 0.1 mbar, which can effectively diminish the influence of $\mathrm{H}_{2} \mathrm{O}$ and $\mathrm{CO}_{2}$ during IR measurement. The base pressure in the IR chamber was $\sim 1 \times 10^{-7}$ mbar. A full-range pressure gauge and a capacitance gauge $(0.1-1000 \mathrm{mbar})$ were connected to the chamber to monitor pressure. The $\mathrm{Ni} / \mathrm{SiO}_{2}$ nanoparticles were pressed on a stainless-steel grid $(100 \mathrm{mesh}, 10 \mathrm{~mm} \times 7 \mathrm{~mm})$ at $20 \mathrm{MPa}$. The stainless-steel grid with sample was fixed between two molybdenum legs by using two tantalum clamps. Sample heating was achieved by applying a voltage between the two molybdenum legs and electrical current that flowed through the grid heated the sample to $1000 \mathrm{~K}$. A K-type thermocouple was welded carefully on the top center of the grid. In the current configuration, in situ transmission IR measurements can be performed under vacuum and with gas exposure conditions at variable sample temperatures. Before the IR measurement, the $\mathrm{Ni} / \mathrm{SiO}_{2}$ catalyst was annealed at $700 \mathrm{~K}$ for $20 \mathrm{~min}$ under a high vacuum to ensure that surface contaminations were removed.

\subsection{Activity Measurement}

The catalytic performance was determined in a fixed-bed reactor. Catalyst $(0.156 \mathrm{~g})$ was placed into a tubular reactor and reduced in a $\mathrm{H}_{2}$ atmosphere for $2 \mathrm{~h}$ at $773 \mathrm{~K}$. After cooling to $523 \mathrm{~K}$, synthesis gas $\left(\mathrm{H}_{2} / \mathrm{CO}=3\right.$, WHSV $\left.=25,000 \mathrm{~mL} \mathrm{~g}^{-1} \mathrm{~h}^{-1}\right)$ was introduced to the tubular reactor and the pressure was increased to $1.5 \mathrm{MPa}$. The catalytic performance was evaluated every $50 \mathrm{~K}$ between 523-823 K, and the effluent-gas composition was analyzed by online gas chromatography (GC-2014C, SHIMADZU, Kyoto, Japan).

\subsection{Density Functional Theory (DFT) Calculations}

DFT calculations were performed using a Dmol3 module that was implemented in a DFT electronic structure program [41-43] GGA/PW91 exchange-correlation functional with DND basis set is used to calculate the exchange correlation energy [44]. The self-consistent field (SCF) procedure is used with the tolerance of $10^{-6}$ au and maximum SCF cycles of 500. The calculated vibrational spectra were picked up and analyzed by Dmol3 module (MS8.0, Dassault Systemes Biovia K.K., San Diego, CA, USA, 2014). The calculated vibrational modes of $\mathrm{CO}$ adsorbed on $\mathrm{Ni} / \mathrm{SiO}_{2}$ catalyst were corrected by the standard gas $\mathrm{CO}$ spectra.

\section{Conclusions}

$\mathrm{A} \mathrm{Ni} / \mathrm{SiO}_{2}$ catalyst was successfully prepared by the $\mathrm{AE}$ method. The $\mathrm{Ni} / \mathrm{SiO}_{2}$ catalyst displayed an excellent catalytic performance over the reaction temperature range with a $96.7 \% \mathrm{CO}$ conversion and 95.6\% $\mathrm{CH}_{4}$ selectivity at $623 \mathrm{~K}$, and $9.5 \mathrm{~s}^{-1} \mathrm{TOF}$ at $523 \mathrm{~K}, 1.5 \mathrm{MPa}$ and a WHSV of $25,000 \mathrm{~mL} \cdot \mathrm{g}^{-1} \cdot \mathrm{h}^{-1}$. The catalyst exhibited an excellent thermostability over $150 \mathrm{~h}$ at $623 \mathrm{~K}$. The in situ VTIR and DFT results demonstrated that the catalysts highly dispersed active sites at the interfaces between the support and active component were responsible for their high catalytic efficiencies. The decrease in particle size of the active component to a single atom may provide excellent catalytic performance. We, therefore, believe that the clarification of active sites provides a strategy to design and prepare high-efficiency CO methanation catalysts.

Author Contributions: F.Y., H.Q. and H.G. designed and administered the experiments. M.Z., P.L. performed experiments. Z.T., J.L., M.Z., W.F. and B.D. collected and analyzed data. All authors discussed the data and wrote the manuscript.

Acknowledgments: This work was financially supported by National Natural Science Foundation of China (U1203293), High-end Talent Team Construction Foundation (No. 108-10000318), Program for Changjiang Scholars and Innovative Research Team in University (No. IRT_15R46) and Program of Science and Technology Innovation Team in Bingtuan (No. 2015BD003).

Conflicts of Interest: The authors declare no conflicts of interests. 


\section{References}

1. Kamata, H.; Tian, Z.Q.; Izumi, Y.; Choong, C.K.S.; Chang, J.; Schreyer, M.; Chen, L.; Borgna, A. Dispersed and high loading Ni catalyst stabilized in porous $\mathrm{SiO}_{2}$ matrix for substituted natural gas production. Catal. Today 2018, 299, 193-200. [CrossRef]

2. Konishcheva, M.V.; Potemkin, D.I.; Snytnikov, P.V.; Stonkus, O.A.; Belyaev, V.D.; Sobyanin, V.A. The insights into chlorine doping effect on performance of ceria supported nickel catalysts for selective CO methanation. Appl. Catal. B Environ. 2018, 221, 413-421. [CrossRef]

3. Wind, T.L.; Falsig, H.; Sehested, J.; Moses, P.G.; Nguyen, T.T.M. Comparison of mechanistic understanding and experiments for CO methanation over nickel. J. Catal. 2016, 342, 105-116. [CrossRef]

4. Li, P.; Yu, F.; Altaf, N.; Zhu, M.; Li, J.; Dai, B.; Wang, Q. Two-Dimensional Layered Double Hydroxides for Reactions of Methanation and Methane Reforming in C1 Chemistry. Materials 2018, 11, 221. [CrossRef] [PubMed]

5. Wang, H.; Xu, K.; Yao, X.; Ye, D.; Pei, Y.; Hu, H.; Qiao, M.; Li, Z.H.; Zhang, X.; Zong, B. Undercoordinated Site-Abundant and Tensile-Strained Nickel for Low-Temperature $\mathrm{CO}_{\mathrm{x}}$ Methanation. ACS Catal. 2018, 1207-1211. [CrossRef]

6. Lv, Y.; Xin, Z.; Meng, X.; Tao, M.; Bian, Z. Ni based catalyst supported on KIT-6 silica for CO methanation: Confinement effect of three dimensional channel on $\mathrm{NiO}$ and $\mathrm{Ni}$ particles. Micropor. Mesopor. Mater. 2018, 262, 89-97. [CrossRef]

7. Vita, A.; Italiano, C.; Pino, L.; Frontera, P.; Ferraro, M.; Antonucci, V. Activity and stability of powder and monolith-coated Ni/GDC catalysts for $\mathrm{CO}_{2}$ methanation. Appl. Catal. B Environ. 2018, 226, $384-395$. [CrossRef]

8. Zhao, B.; Chen, Z.; Chen, Y.; Ma, X. Syngas methanation over Ni/SiO 2 catalyst prepared by ammonia-assisted impregnation. Int. J. Hydrogen Energy 2017, 42, 27073-27083. [CrossRef]

9. Lai, Y.Q.; Wang, Q.Y.; Wang, M.R.; Li, J.; Fang, J.; Zhang, Z.A. Facile synthesis of mesoporous Fe-N-C electrocatalyst for high performance alkaline aluminum-air battery. J. Electroanal. Chem. 2017, 801, 72-76. [CrossRef]

10. Yan, X.; Liu, Y.; Zhao, B.; Wang, Z.; Wang, Y.; Liu, C.-J. Methanation over $\mathrm{Ni} / \mathrm{SiO}_{2}$ : Effect of the catalyst preparation methodologies. Int. J. Hydrogen Energy 2013, 38, 2283-2291. [CrossRef]

11. Zhao, B.; Chen, Z.; Yan, X.; Ma, X.; Hao, Q. CO Methanation over Ni/SiO 2 Catalyst Prepared by Ammonia Impregnation and Plasma Decomposition. Top. Catal. 2017, 60, 879-889. [CrossRef]

12. Li, P.; Zhu, M.; Dan, J.; Kang, L.; Lai, L.; Cai, X.; Zhang, J.; Yu, F.; Tian, Z.; Dai, B. Two-dimensional porous $\mathrm{SiO}_{2}$ nanomesh supported high dispersed Ni nanoparticles for $\mathrm{CO}$ methanation. Chem. Eng. J. 2017, 326, 774-780. [CrossRef]

13. Yao, Y.; Goodman, D.W. In situ IR spectroscopic studies of Ni surface segregation induced by CO adsorption on $\mathrm{Cu}-\mathrm{Ni} / \mathrm{SiO}_{2}$ bimetallic catalysts. Phy. Chem. Chem.Phy. 2014, 16, 3823-3829. [CrossRef] [PubMed]

14. Loc, L.C.; Huan, N.M.; Gaidai, N.A.; Thoang, H.S.; Nekrasov, N.V.; Agafonov, Y.A.; Lapidus, A.L. Reaction mechanism of $\mathrm{CO}$ methanation on nickel catalysts, as studied by isotopic and nonstationary methods. Kinet. Catal. 2011, 52, 749-755. [CrossRef]

15. Martra, G.; Swaan, H.M.; Mirodatos, C.; Kermarec, M.; Louis, C. Sintering of Ni/SiO 2 catalysts prepared by impregnation and deposition-precipitation during CO hydrogenation. Stud. Surf. Sci. Catal. 1997, 111, 617-624.

16. Primet, M.; Dalmon, J.A.; Martin, G.A. Adsorption of $\mathrm{CO}$ on well-defined Ni/SiO 2 catalysts in the $195-373 \mathrm{~K}$ range studied by infrared spectroscopy and magnetic methods. J. Catal. 1977, 46, 25-36. [CrossRef]

17. Gao, J.; Jia, C.; Zhang, M.; Gu, F.; Xu, G.; Su, F. Effect of nickel nanoparticle size in $\mathrm{Ni} / \alpha-\mathrm{Al}_{2} \mathrm{O}_{3}$ on $\mathrm{CO}$ methanation reaction for the production of synthetic natural gas. Catal. Sci. Technol. 2013, 3, $2009-2015$. [CrossRef]

18. Feng, J.-T.; Lin, Y.-J.; Evans, D.G.; Duan, X.; Li, D.-Q. Enhanced metal dispersion and hydrodechlorination properties of a Ni/ $\mathrm{Al}_{2} \mathrm{O}_{3}$ catalyst derived from layered double hydroxides. J. Catal. 2009, 266, 351-358. [CrossRef]

19. Agnelli, M.; Swaan, H.M.; Marquez-Alvarez, C.; Martin, G.A.; Mirodatos, C. CO Hydrogenation on a Nickel Catalyst: II. A Mechanistic Study by Transient Kinetics and Infrared Spectroscopy. J. Catal. 1998, 175, 117-128. [CrossRef] 
20. Liu, B.; Yao, N.; Li, S.; Wang, J.; Lv, D.; Li, X. Methanation of CO in hydrogen-rich gas on Ni-Ru/SiO 2 catalyst: The type of active sites and Ni-Ru synergistic effect. Chem. Eng. J. 2016, 304, 476-484. [CrossRef]

21. Zhi, C.; Wang, Q.; Wang, B.; Li, D.; Zhang, R. Insight into the mechanism of methane synthesis from syngas on a Ni(111) surface: a theoretical study. RSC Adv. 2015, 5, 66742-66756. [CrossRef]

22. Han, X.; Yang, J.; Guo, H.; Qin, Z.; Zhao, S.; Lu, Y.; Li, Z.; Ren, J. Mechanism studies concerning carbon deposition effect of $\mathrm{CO}$ methanation on Ni-based catalyst through DFT and TPSR methods. Int. J. Hydrogen Energy 2016, 41, 8401-8411. [CrossRef]

23. Layman, K.A.; Bussell, M.E. Infrared Spectroscopic Investigation of CO Adsorption on Silica-Supported Nickel Phosphide Catalysts. J. Phy. Chem. B 2004, 108, 10930-10941. [CrossRef]

24. Konishcheva, M.V.; Potemkin, D.I.; Badmaev, S.D.; Snytnikov, P.V.; Paukshtis, E.A.; Sobyanin, V.A.; Parmon, V.N. On the Mechanism of $\mathrm{CO}$ and $\mathrm{CO}_{2}$ Methanation Over Ni/CeO 2 Catalysts. Top. Catal. 2016, 59, 1424-1430. [CrossRef]

25. Westermann, A.; Azambre, B.; Bacariza, M.C.; Graça, I.; Ribeiro, M.F.; Lopes, J.M.; Henriques, C. Insight into $\mathrm{CO}_{2}$ methanation mechanism over NiUSY zeolites: An operando IR study. Appl. Catal. B Environ. 2015, 174-175, 120-125.

26. Zhu, X.; Cheng, D.; Kuai, P. Catalytic Decomposition of Methane over Ni/ $\mathrm{Al}_{2} \mathrm{O}_{3}$ Catalysts: Effect of Plasma Treatment on Carbon Formation. Energy Fuels 2008, 22, 1480-1484. [CrossRef]

27. Zhang, C.; Yue, H.; Huang, Z.; Li, S.; Wu, G.; Ma, X.; Gong, J. Hydrogen Production via Steam Reforming of Ethanol on Phyllosilicate-Derived $\mathrm{Ni} / \mathrm{SiO}_{2}$ : Enhanced Metal-Support Interaction and Catalytic Stability. ACS Sustain.Chem. Eng. 2013, 1, 161-173. [CrossRef]

28. Zhang, Q.; Wang, M.; Zhang, T.; Wang, Y.; Tang, X.; Ning, P. A stable Ni/SBA-15 catalyst prepared by the ammonia evaporation method for dry reforming of methane. RSC Adv. 2015, 5, 94016-94024. [CrossRef]

29. Dębek, R.; Motak, M.; Galvez, M.E.; Grzybek, T.; Da Costa, P. Promotion effect of zirconia on $\mathrm{Mg}(\mathrm{Ni}, \mathrm{Al}) \mathrm{O}$ mixed oxides derived from hydrotalcites in $\mathrm{CO}_{2}$ methane reforming. Appl. Catal. B Environ. 2018, 223, 36-46. [CrossRef]

30. Kadirvelu, K.; Thamaraiselvi, K.; Namasivayam, C. Removal of heavy metals from industrial wastewaters by adsorption onto activated carbon prepared from an agricultural solid waste. Bioresour. Technol. 2001, 76, 63-65. [CrossRef]

31. Lakshmanan, P.; Kim, M.S.; Park, E.D. A highly loaded $\mathrm{Ni} @ S i O_{2}$ core-shell catalyst for CO methanation. Appl. Catal. A Gen. 2016, 513, 98-105. [CrossRef]

32. Damyanova, S.; Pawelec, B.; Palcheva, R.; Karakirova, Y.; Sanchez, M.C.C.; Tyuliev, G.; Gaigneaux, E.; Fierro, J.L.G. Structure and surface properties of ceria-modified Ni-based catalysts for hydrogen production. Appl. Catal. B Environ. 2018, 225, 340-353. [CrossRef]

33. Sun, K.-Q.; Marceau, E.; Che, M. Evolution of nickel speciation during preparation of $\mathrm{Ni}^{-\mathrm{SiO}_{2}}$ catalysts: effect of the number of chelating ligands in $\left[\mathrm{Ni}(\mathrm{en})_{\mathrm{x}}\left(\mathrm{H}_{2} \mathrm{O}\right)_{6-2 \mathrm{x}}\right]^{2+}$ precursor complexes. Phy. Chem. Chem. Phy. 2006, 8, 1731-1738. [CrossRef] [PubMed]

34. Li, P.; Wen, B.; Yu, F.; Zhu, M.; Guo, X.; Han, Y.; Kang, L.; Huang, X.; Dan, J.; Ouyang, F.; et al. High efficient nickel/vermiculite catalyst prepared via microwave irradiation-assisted synthesis for carbon monoxide methanation. Fuel 2016, 171, 263-269. [CrossRef]

35. Le, T.A.; Kim, M.S.; Lee, S.H.; Kim, T.W.; Park, E.D. CO and $\mathrm{CO}_{2}$ methanation over supported Ni catalysts. Catal. Today 2017, 293-294, 89-96.

36. Politano, A.; Chiarello, G. Vibrational Investigation of Catalyst Surfaces: Change of the Adsorption Site of CO Molecules upon Coadsorption. J. Phy. Chem. C 2011, 2, 514-517. [CrossRef]

37. Politano, A.; Chiarello, G. Carbon monoxide interaction with oxygenated nickel single-crystal surfaces studied by vibrational spectroscopy. Vib. Spectrosc. 2011, 55, 295-299. [CrossRef]

38. Politano, A.; Chiarello, G. The formation of HOCO in the coadsorption of water and carbon monoxide on Pt3Ni(111). RSC Adv. 2014, 4, 45641-45646. [CrossRef]

39. Chiarello, G.; Marino, A.R.; Formoso, V.; Politano, A. The adsorption and co-adsorption of oxygen and carbon monoxide on $\mathrm{Pt}_{3} \mathrm{Ni}$ (111): A vibrational study. J. Chem. Phy. 2011, 134, 224705. [CrossRef] [PubMed]

40. Politano, A.; Vitiello, M.S.; Viti, L.; Hu, J.; Mao, Z.; Wei, J.; Chiarello, G. Unusually strong lateral interaction in the CO overlayer in phosphorene-based systems. Nano Res. 2016, 9, 2598-2605. [CrossRef]

41. Delley, B. An all-electron numerical method for solving the local density functional for polyatomic molecules. J. Chem. Phy. 1990, 92, 508-517. [CrossRef] 
42. Delley, B. From molecules to solids with the DMol3 approach. J. Chem. Phy. 2000, 133, 7756-7764. [CrossRef]

43. Gao, H. A first principles investigation of the $\mathrm{NO}$ oxidation mechanism on $\mathrm{Pt} / \gamma-\mathrm{Al}_{2} \mathrm{O}_{3}$. RSC Adv. 2016, 6, 102914-102923. [CrossRef]

44. Perdew, J. P.; Wang, Y. Accurate and simple analytic representation of the electron-gas correlation energy. Phy. Rev. B 1992, 45, 13244-13249. [CrossRef] 